\title{
Reconstruction of Urban Management Image in Network Communication Environment
}

\author{
Mengyu Li \\ Henan University of Animal Husbandry \& Economy, Henan, China \\ limengyu09@126.com
}

Keywords: Internet communication, Urban management image, Reconstruction.

\begin{abstract}
City is a symbol of the economic and cultural development for a country or region. Urban management plays a very important role in the normal operation of the city. The establishment of a city management department has attracted a large number of practitioners, they are the so-called urban managements. In response to online media reports and comments of netizen, the impact of public opinion on the image of urban management was analyzed. The advantages and disadvantages of online media in reporting on urban management issues were studied, and strategies were proposed for the remodeling of urban management so as to stabilize the government's management and social order. The study of the paper has a certain theoretical guiding significance for promoting the healthy development of urban management.
\end{abstract}

\section{Introduction}

In recent years, with the strengthening of urban management, the conflicts and contradictions between some urban management and mobile vendors have increased. The overall image of urban management in people's hearts has also been constantly labeled as negative [1]. The construction of urban management image in the network dissemination was originated from the reports of online media and the active participation and hot discussion of netizen. The causes of the crisis in the image of urban management are complex and multifaceted. It is difficult to fundamentally solve the problem by simply attempting to change the image of urban management through regulating the enforcement actions of urban management members [2].

The various factors that affect the image of urban management can be observed and analyzed from multiple perspectives, and then reasonable countermeasures can be used to actively reshape and enhance the image of urban management, thus providing an important guarantee for urban management.

\section{Current status of urban management image in network communication}

With the continuous development of the market economy and the accelerating process of urbanization, new contradictions continue to occur in the urban management of our country. As the city's administrative law enforcement becomes more and more difficult to carry out, the urban management department emerged as a result, with a view to improving the efficiency of urban management. It is mainly responsible for solving the dirty, chaotic, and bad conditions of the city, and it is also working with other departments on the city's environmental protection, municipal administration, and garden development [3].

Concerning the connotation of the image of urban management, there is currently no unified understanding. Generally speaking, the image of urban management refers to the overall impression and comprehensive evaluation of the urban public management department and its staff from the citizens. Urban management's responsibility is to manage the illegal and non-compliant activities in the city. Therefore, it is very powerful in the enforcement process, especially in the face of mobile vendors, in order to complete the so-called achievements, it is not surprising that there has been brutal law enforcement. In fact, Urban management's role is to ensure that the city is clean, tidy, and orderly and seldom considers the needs of the public. Therefore, it is often considered as an arrogant, 
overbearing, and brutal image of law enforcement officials, while traders are shaped as industrious, simple and vulnerable group who relying on their own labor to work hard for the life [4].

From the perspective of social construction, urban management is not a fixed social existence but an image formed in the virtual discussion between the media and netizens. Even the misconduct and behavior of some officials and rich people may also cause netizens' bad references to this group of urban management. In a certain sense, netizens' pursuit of the right to information has promoted the development of online news services, improved the status of online media, and promoted news reforms in China. At the same time, it has continued to promote the disclosure of government information and the improvement of government work.

\section{Main reasons for the negative image of urban management in network communication}

\subsection{Inaccurate report of urban management by online media}

Through the combing of online media about urban management related news reports in recent years, in addition to the sensational "headline" and reports that do not correspond to objective reality, there were also problems with no end. After the attention of netizen was attracted, the online media did not track it down. Lacking of comprehensive and in-depth reporting, which not only damaged the image of the city administration, but also caused the society's "stereotype" of urban management, which also affected the credibility of the government [5].

In order to attract the public's attention, some online media catered to the vulgar interests of some netizen, while "concocting" news and making scary titles, choosing to report the events such as "street dealers being beaten by urban management" and "urban violence", shaped the negative image of urban management.

\subsection{Netizens' perceptions and attitudes towards urban management}

While enjoying the free environment of the internet, netizens should take the initiative to assume their due network responsibilities and obligations, and cannot be considered as "keyboard man". In an anonymous network environment, it is difficult to achieve an objective and fair judgment of urban management groups based solely on old image.

Internet information mainly depends on the reading, commenting, and forwarding of internet users to spread. Therefore, the irrational emotions of netizens are misdirected and it is easy to misunderstand the urban management groups, which leads to a negative evaluation of the image of urban management.

\section{The effective measures to reshape the image of urban management}

\subsection{The improvement of self-cultivation of urban management team}

First of all, it is necessary to strictly control the recruitment of urban management, and to select the proper staffs in accordance with relevant requirements to improve the overall quality of the urban management team. Second, it is necessary to train the urban management on their legal awareness and law enforcement capabilities. In the process of training, we must follow the psychological characteristics and occupational characteristics of urban management practitioners, enhance professional identity, and ensure that the internal control of the group can be enhanced. The cultivation of legal ideas can not only enhance the ideological awareness and business level of law enforcers, but also improve the overall atmosphere of standardizing law enforcement and civilized law enforcement, and constantly shape the good image of urban management [6].

At the same time, the urban management team should enhance its ability to use the network, establish its own voice channel and a spokesman system for urban management news, and strive to eliminate the "aphasia" phenomenon of urban management, eliminate adverse impacts timely, and actively shape the organizational image of urban management. In addition, the urban management 
department should establish their own team of commentators and use their analytical and discourse abilities of internet public opinion to positively guide and control the direction of public opinion.

\subsection{Strict supervision of urban management related news}

When it comes to the relevant news of urban management, it must be true, broad, and comprehensive to present and report, so that netizens can understand the context of the incident. In the discussion of participation events, the influence of the agenda can be used to guide the thinking and speech of netizens, and online media should do a good job of "checking" the information content and avoiding the "headline party". For the relevant contents of urban management, online media not only needs to improve the auditing requirements, but also strictly checks the contents of the information. Moreover, after the relevant online media specifications have been issued, they can react more accurately so as to prevent online speech from getting out of control [7].

In addition, online media also learned to use the government's official release to increase the credibility of information through the government's strength and avoid becoming a so-called "weapon of the weak". Urban management has changed from a city manager to a service provider, and more and more information points to urban management's contribution to urban development. From the original hate to the state that can be understood, the power of the network must not be underestimated. With an open network environment, online media needs to stick to their own media responsibilities and deal with public opinion related to urban management with new ideas and methods.

\subsection{Urban management system needs continuous optimization}

The responsibilities and requirements of the city management are more clarified, and it can ensure that the city management complies with the laws and job requirements in the law enforcement process so as to achieve the legal right. However, to fundamentally reverse the image of urban management, it is necessary to change the concept of law enforcement, from the original administrator to a service provider. In the process of comprehensive urban governance, we must not adopt simple and brutal methods. Instead, the needs of humanity and reflect humanistic care should be considered in the work.

On the one hand, urban management and hawkers should understand and trust each other. The urban management should fully understand the hardships of the underlying society, and the hawkers must also understand the urban management professional requirements and all kinds of difficulties. On the other hand, they can learn about relevant foreign urban management methods and ways to achieve self-management and reduce friction with each other.

\subsection{Netizens should be cautious about the information of urban management}

In the process of online dissemination related to urban management, individual subjective consciousness is inevitable. It is common to invent, exaggerate, and fabricate false information. This requires netizens to improve their own net literacy, firstly check the source of the information, confirm the authenticity of the information, and then forward and comment on it to avoid publishing inappropriate comments on the prejudice of the urban management group. Netizens should also rationally deal with urban management-related sensibilities and avoid publishing irresponsible remarks as a result of the network's indignation and damage the image of urban management.

\subsection{The government should sound in time}

In the process of network information dissemination, the government's voice must not only be timely but also accurate. After the incidents related to urban management were exposed, the government must first quantify the incident, conduct investigations, follow up it timely, organize media and social personnel to participate in the discussion in an orderly manner, and respond to it positively. The symmetry of information between the government and netizens must not be a pressure on the netizens' questions, but they should actively respond to them and reduce the negative effects of the internet. 
In addition, the government should also establish information publishing platforms to adapt to the development of the internet era. With the awakening of netizens' democratic awareness, more and more netizens are concerned about public affairs. Therefore, not only the government Websites, official Micro-blog and We-Chat public numbers should be opened, but also they should actively interact with netizens and listen to the voice of folks as a reference for decision-making to enhance the transparency of government

\subsection{The state must improve relevant laws}

The rapid development of the city requires more effort from city managers. For a neat city appearance and convenient transportation, it is necessary not only to divert mobile vendors but also to require the participation of all parties. Urban management's penalties for vendors are not the purpose, so the basis for its law enforcement needs to be further improved. At the same time, the relevant rights and interests of law enforcers must also be protected. The state must earnestly do a good job in the relevant legislative work to protect the legitimate rights and interests of law enforcement and law enforcement objects so as to better promote the harmonious development of society.

\section{Summary}

The remodeling of urban management image is a complicated process, and it is also a difficult problem for city management. The true image of urban management can be presented only through the efforts of many parties and the social role of urban management can be maximized and an important guarantee for the standardized management of the city can be provided in the future.

\section{Acknowledgement}

This research was financially supported by the Henan Provincial Department of Education Humanities and Social Sciences Project (Grant NO. 2018-ZDJH-125) .

\section{References}

[1] C. Huang, The origin of the image crisis of city tubular and its way to remoulds, Journal of Fujian Administration Institute, vol.1, pp. 29-32, 2011.

[2] S. J. Fan, Dilemma and surmount of the binary contradiction between subject and object in city management, Journal of Jiangsu Administration Institute, vol.2, pp. 107-111, 2010.

[3] M. Wang, The "stigma" effect of internet public opinion and "most tyranny", Party Vision, vol.2, pp. 51-52, 2012.

[4] X. H. Zhou, Viewing crisis communication management from the image of urban management network demonization, Communication and Copyright, vol. 12, pp. 153-154, 2014.

[5] H. Y. Li and W. L. Cao, An analysis of the social responsibility of the mass media in social changes: Taking the image of migrant workers' TV images in "Chinese Migrant Workers" as an example, TV Research, vol. 5, pp. 47-50, 2011.

[6] X. Y. Shen, Urban governance from a multi-center perspective: Practical significance and predicament, Economist, vol. 10, pp. 50-51, 2010.

[7] W. Zheng, The perspective of the cause of urban governance image crisis and its countermeasures, Theory, vol. 11, pp. 25-26, 2014. 